\title{
Dentinogênese imperfeita: caso familiar
}

\author{
Dentinogenesis imperfecta: family case
}

\author{
Viviane P. da Silva* \\ Juliana A. Cardoso* \\ Maria P. Barreto ${ }^{* * *}$ \\ Suelen da Guarda ${ }^{* * * *}$ \\ Ariana G. Carneiro \\ Jener G. Farias ${ }^{* * * *}$
}

\section{Resumo}

Objetivo: este estudo relata o método de diagnóstico utilizado para identificar dentinogênese imperfeita em seis pacientes da mesma família. Relato de casos: o diagnóstico familiar foi estabelecido com base na anamnese do probando, sendo, posteriormente, chamados os outros membros familiares a comparecerem ao atendimento. Uma análise conjunta de exames clínico, físico, de imagem e bioquímicos foi realizada para conclusão do diagnóstico final. O protocolo de tratamento foi realizado individualmente, de acordo com o quadro clínico de cada paciente. Considerações finais: a dentinogênese imperfeita é considerada um distúrbio genético do desenvolvimento da dentina que ocorre na ausência de desordens sistêmicas. Apresenta um padrão autossômico dominante e pode ser causada por mutações no gene sialofosfoproteína da dentina - DSPP. Clinicamente, pode apresentar translucência de esmalte, coloração escura e fragilidade dentinária, o que pode levar a graves prejuízos funcionais e estéticos para o paciente. Por essas razões, o diagnóstico deve ser realizado de forma minuciosa e precocemente, evitando, assim, intervenções terapêuticas mais complexas com o passar da idade.

Palavras-chave: Complicações. Dentinogênese imperfeita. Diagnóstico. Patologia.

\section{Introdução}

A dentinogênese imperfeita (DI) acomete cerca de 1:8000 brancos nos Estados Unidos da América ${ }^{1}$, caracteriza-se por ser um distúrbio de caráter genético e é causada por mutações no gene sialofosfoproteína da dentina (DSPP). O gene DSPP está localizado no cromossoma 4q21.3, o qual é responsável por codificar grande parte das proteínas não colagenosas da dentina. Mutações nesse gene podem desativar ou interferir indiretamente no metabolismo dessas proteínas e, com isso, alterar a composição e a formação da dentina de diferentes formas. Esse fator pode justificar as variações nas expressões clínicas e radiográficas da dentinogênese imperfeita ${ }^{2-4}$.

Devido a essa variabilidade de manifestações clínicas dos casos de dentinogênese imperfeita, ela pode ser classificada nos tipos I, II e III ${ }^{5,6}$. O tipo I ocorre associado à osteogênese imperfeita (OI). Ao exame clínico, a cor da dentição pode variar do cinza ao violeta-acastanhado ou castanho-amarelado, todos apresentando uma tonalidade opalescente ou translúcida ${ }^{4,6}$. As coroas apresentam-se curtas com sinais de exposição de dentina e desgastes coronários $^{1}$. Radiograficamente, há um aspecto característico de dentes com coroas de forma bulbosa e pre-

Doutoranda da Universidade Federal do Rio Grande do Sul. Instituição: União Metropolitana de Educação e Cultura e Universidade Federal do Rio Grande do Sul, Porto Alegre, Rio Grande do Sul, Brasil.

Professora União Metropolitana de Educação e Cultura, Lauro de Freitas, Bahia, Brasil.

Professora da Universidade Estadual de Feira de Santana, Feira de Santana, Bahia, Brasil.

Especialista em Estomatologia, União Metropolitana de Educação e Cultura, Lauro de Freitas, Bahia, Brasil.

Professor da União Metropolitana de Educação e Cultura e da Universidade Estadual de Feira de Santana, Lauro de Freitas, Bahia, Brasil. 
sença de constrição cervical acentuada. Observa-se, também, obliteração precoce total ou parcial das câmaras pulpares e dos canais radiculares, ocasionada pela formação contínua de dentina ${ }^{4,6}$. Apesar de as raízes serem curtas e rombas, o cemento e o osso de suporte são normais ${ }^{4,6}$.

As características clínicas e radiográficas da DI do tipo II são iguais às do tipo I. O que diferencia esses dois tipos de anomalias é a ausência da osteogênese imperfeita na dentinogênese imperfeita tipo $\mathrm{II}^{1,4,6}$. A dentinogênese imperfeita tipo III é a forma mais rara e caracteriza-se pelos mesmos aspectos clínicos dos tipos I e II, associados a exposições múltiplas das polpas dos dentes decíduos. Dentre os aspectos radiográficos, observa-se uma grande amplitude das câmaras pulpares, paredes dentinárias finas e canais radiculares grandes ${ }^{1,4}$. $\mathrm{O}$ diagnóstico diferencial da DI deve ser feito entre os seus três tipos e a displasia dentinária, que apresenta características clínicas bastante semelhantes à dentinogênese imperfeita ${ }^{1}$.

No passado, a maioria dos casos de dentinogênese imperfeita foi deixada sem tratamento até ocorrer a maturidade dos elementos dentários, quando eram extraídos e substituídos por próteses totais. Atualmente, sabe-se que é necessário que o tratamento comece na infância e termine na fase adulta, o qual irá depender da idade e do tipo da DI7. O ideal é, em qualquer fase, usar estratégias que ob- jetivem restabelecer a dimensão vertical perdida, a função, a estética e a fonética do paciente ${ }^{8}$. A literatura descreve uma vasta opção de tratamentos para os diferentes tipos de DI, usando, por exemplo: restaurações de resina, coroas protéticas, próteses parciais removíveis, implantes dentários, tratamento endodôntico e ortodôntico ${ }^{1,6,8-13}$.

$\mathrm{O}$ presente artigo objetiva relatar o método de diagnóstico utilizado para identificar DI em três gerações de uma mesma família.

\section{Relato de casos}

\section{- Caso I: probando - paciente com 23 anos (Figura 1 A e B)}

Paciente, sexo masculino, 23 anos de idade, foi encaminhado para consulta odontológica com a queixa de insatisfação com a aparência dos seus dentes. Apresentava, clínica e radiograficamente, as seguintes características: coloração dos dentes amarelo-acastanhada, desgastes coronários, coroas bulbosas, constrição cervical, ausência de várias unidades e mobilidade em outras, câmaras pulpares obliteradas e raízes encurtadas. O paciente utilizava uma prótese parcial removível superior mal adaptada, que não o satisfazia funcional e esteticamente.

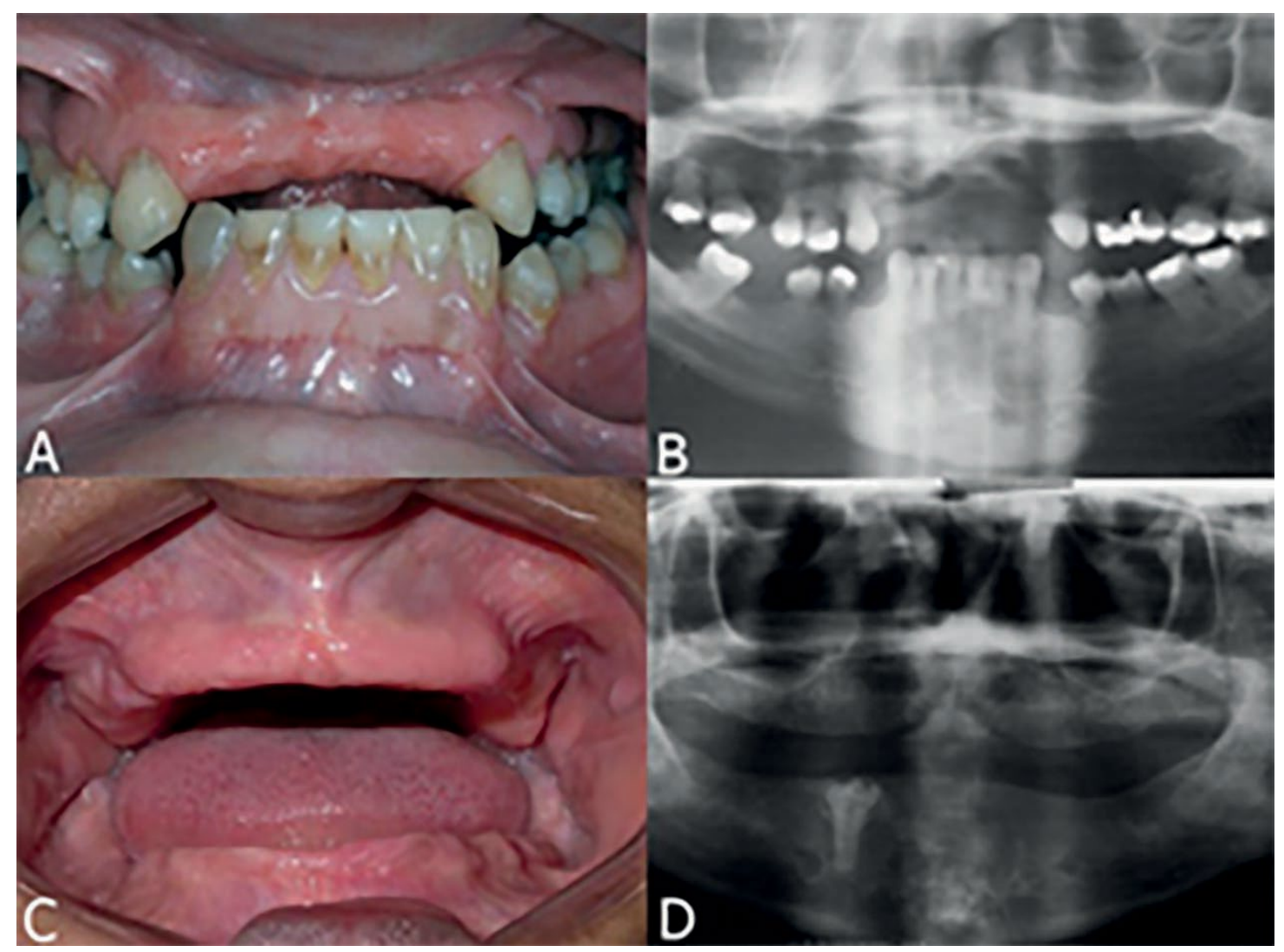

Figura 1 - Fotografias oclusais e radiografias panorâmicas

A e B paciente I; C e D paciente II.

Fonte: elaboração dos autores. 
Durante a anamnese, ao ser questionado sobre problemas semelhantes na família, o probando relatou que sua irmã era edêntula e que seus sobrinhos apresentavam dentes com certa mobilidade e coloração diferente do normal. Os familiares foram convidados para observação clínica e, diante dos aspectos clínicos apresentados, foram solicitados exames radiográficos e laboratoriais.

\section{- Caso II: irmã de 30 anos (Figura 1 C e D)}

Paciente edêntula que, ao exame radiográfico, exibia uma unidade dentária impactada, com constrição cervical e obliteração parcial da câmara pul- par. Foi relatado histórico de dentes frágeis, sensíveis e com coloração levemente marrom.

\section{- Caso III: primo de 14 anos (Figura 2 A e B)}

Notou-se uma leve coloração amarelo-acinzentada, as coroas de dentes posteriores exibiram sinais de exposição de dentina e desgastes coronários profundos. Radiograficamente, as coroas apresentaram-se bulbosas e com constrição cervical. As raízes dentárias eram pequenas e com poucos sinais de obliteração. Alguns dentes com a amplitude alargada da câmara pulpar e paredes dentinárias finas.

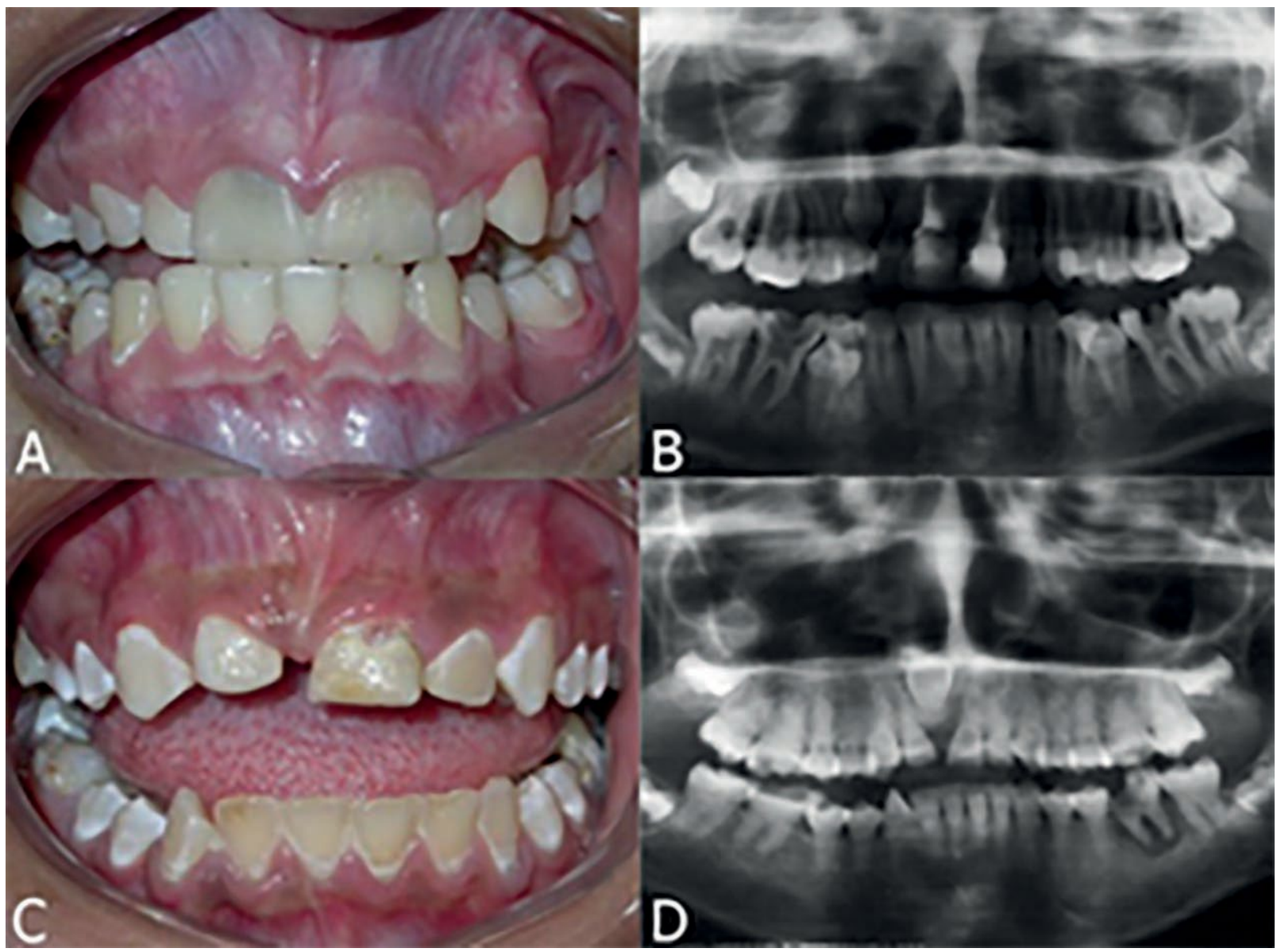

Figura 2 - Fotografias oclusais e radiografias panorâmicas

A e B paciente III; C e D paciente IV.

Fonte: elaboração dos autores.

\section{- Caso IV: sobrinho de 9 anos (Figura 2 C e D)}

Paciente encontrava-se na fase da dentição mista. A dentição permanente foi a mais alterada, com coloração acinzentada e translucência de esmalte. Radiograficamente, um caso clássico de coroas bulbosas, constrição cervical, raízes curtas e rombas, relação do tamanho coroa/raiz desproporcional e obliteração das câmaras pulpares.
- Caso V: sobrinha de 8 anos (Figura 3 A e B)

Paciente de 8 anos de idade, com a dentição permanente apresentando coloração amarelo-acastanhada e translucência de esmalte. No exame radiográfico, ambas as dentições estavam alteradas, demonstrando constrição cervical, coroas bulbosas, raízes pequenas e obliteração total de câmeras pulpares e canais radiculares. 


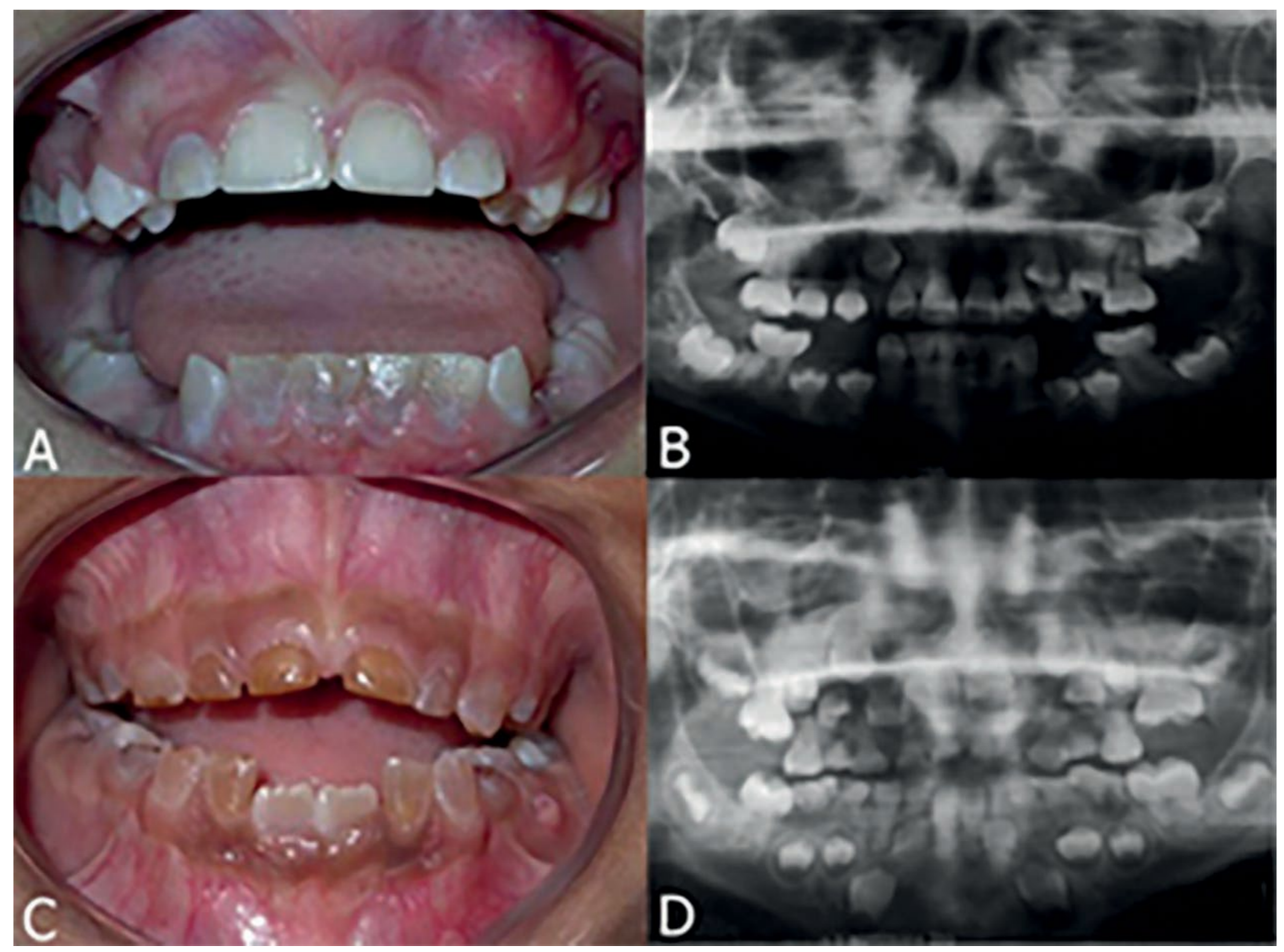

Figura 3 - Fotografias oclusais e radiografias panorâmicas

A e B paciente V; C e D paciente VI.

Fonte: elaboração dos autores.

\section{- Caso VI: sobrinho de 5 anos (Figura 3 C e D)}

Esteticamente, a dentição decídua exibiu uma coloração amarelo-amarronzada, com exposição de dentina e destruições coronárias. A radiografia demostrou presença de raízes curtas, constrição cervical e coroas bulbosas em ambas as dentições. Observou-se também obliteração das raízes e das câmaras pulpares, principalmente na dentição decídua.

Diante de tais características familiares, confirmou-se a hereditariedade da doença e surgiram duas hipóteses diagnósticas, as quais foram: dentinogênese imperfeita e displasia dentinária.

$\mathrm{Na}$ displasia dentinária tipo I, as coroas dos dentes não apresentam alterações clínicas. Tal comportamento não foi visualizado nos pacientes apresentados e, por isso, foi descartada essa hipótese. A suspeita de displasia dentinária tipo II também foi eliminada devido à ausência de extensão apical dos canais radiculares e à ausência de câmaras pulpares aumentadas ${ }^{1,3-5}$.

A dentinogênese imperfeita tipo I foi descartada devido à ausência de osteogênese imperfeita. Para isso, investigaram-se a presença de esclera azul, li- gamentos flácidos e ossos frágeis, foram realizadas radiografias de ossos longos e níveis séricos de cálcio, fósforo e fosfatase alcalina. Os exames clínicos, imaginológicos e bioquímicos não apresentaram alterações.

A dentinogênese imperfeita tipo III foi descartada porque os pacientes não apresentaram múltiplas exposições pulpares associadas a alargamento da amplitude das câmaras pulpares, paredes dentinárias finas e canais radiculares grandes. Assim, por todos os aspectos observados, admite-se ser um caso familiar de DI do tipo II.

A escolha do protocolo de tratamento dos pacientes foi determinada de acordo com o tipo de DI e com as condições financeiras da família. Para o probando, sugeriu-se a realização de cirurgia ortognática para tentar redução de mento, ajuste oclusal e expansão maxilar com intuito de corrigir o padrão esquelético classe III. Posteriormente, foi indicado, para o probando e a paciente II, a remoção das unidades dentárias remanescentes, a colocação de implantes e a reabilitação com prótese sobre implante.

Nos casos III, IV, V e VI, foi proposto um tratamento em que se preconizou restabelecer a dimensão vertical perdida, a função e a estética dos 
pacientes. Foi indicada a realização de extrações, endodontias e algumas restaurações para adequação funcional e estética. Em um segundo momento, foi sugerida a realização da reabilitação protética com intuito de manter espaço e a dimensão vertical.

Os pacientes foram encaminhados para diferentes especialidades odontológicas para realização do tratamento e assinaram o termo de consentimento livre e esclarecido, autorizando a publicação de fotos e casos apresentados.

\section{Discussão}

A classificação de dentinogênese imperfeita já foi motivo de discussão entre muitos autores. Os sistemas mais aceitos são os sugeridos por Shields, em 1973, e por Witkop, em 1989, que se basearam apenas em características clínicas. Embora os critérios de classificação de ambos sejam os mesmos, Shields classificou a DI em três tipos: I, II e III ${ }^{8,14}$, e Witkop classificou-a em: dentinogênese imperfeita, dentes opalescentes hereditários e Brandywine isolado $^{10}$. A classificação utilizada no caso clínico relatado foi a proposta por Shields.

Clinicamente, a dentinogênese imperfeita apresenta-se com o esmalte normal, porém com uma variada translucência, a qual pode criar uma aparência azulada ou violeta ou amarelo-acastanhada. Frequentemente, as radiografias apresentam-se com coroas dentárias de forma bulbosa e com constrição de colo ${ }^{4,6}$. Todas essas características estiveram presentes nos pacientes relatados e foram de grande importância para realização do diagnóstico entre os tipos de DI.

É importante salientar que a presença da osteogênese imperfeita é uma condição imprescindível para determinar a DI tipo I. Para diagnosticá-la, devem-se analisar os aspectos clínicos e radiográficos, investigar os antecedentes familiares e relatos de fratura óssea por traumas considerados leves, considerando associação com exames complementares, tais como: radiografias dos ossos longos, radiografias de tórax; radiografia do crânio; telerradiografia do crânio e exame da dosagem de cálcio sérico ${ }^{14}$. Vale ressaltar que, no quadro laboratorial da OI, a fosfatase alcalina sérica encontra-se frequentemente aumentada, não sendo observadas, porém, alterações nos níveis de cálcio e fósforo ${ }^{14}$. Foram realizados todos os exames radiográficos e laboratoriais, além de uma anamnese precisa e detalhada, para excluir essa hipótese da presença da osteogênese imperfeita nos casos relatados.

A displasia dentinária (DD) é um distúrbio genético que apresenta características clínicas bastante semelhantes à dentinogênese imperfeita. Por esse motivo, se faz necessária a realização de diagnóstico diferencial entre essas anomalias ${ }^{6,9}$. Existem dois tipos de DD: tipos I e II. Na DD tipo I, os dentes envolvidos apresentam aspectos clínicos normais ${ }^{14}$, porém exibem mobilidade e esfoliação prematura, espontânea ou secundária ao menor trauma ${ }^{15}$, o que é justificado pela presença de raízes curtas e mal formadas, conforme exames radiográficos ${ }^{1,14}$. Na DD tipo II, os dentes apresentam características clínicas semelhantes à DI tipo II, por isso, o diagnóstico diferencial baseia-se nas características radiográficas, em que as câmaras pulpares mostram aumento significativo e extensão apical ${ }^{1}$.

Destaca-se a necessidade de uma análise minuciosa das características clínicas, radiográficas e sistêmicas dos pacientes para o estabelecimento de um diagnóstico correto. Pois vários tipos de tratamento de DI foram descritos na literatura, mudando de acordo com a expressividade da doença, e o sucesso do tratamento dependerá da precisão do diagnóstico.

O tratamento endodôntico em pacientes com DI do tipo I e II, por exemplo, pode resultar em complicações, pois a maioria dos canais radiculares são estreitos ou inexistentes, devido à obliteração desses pela deposição de dentina terciária ou reparadora constante ${ }^{10}$. Entretanto, se os canais forem encontrados, os procedimentos podem prosseguir normalmente. O único obstáculo é que as restaurações de pino e de núcleo do molde têm um prognóstico questionável, devido às mudanças morfológicas da dentina e à probabilidade aumentada da fratura ${ }^{7}$. Em pacientes com DI tipo III de Brandywine, que apresentam ampliação da câmara pulpar, pode não haver dificuldades para realizar o tratamento endodôntico ${ }^{1,8-10}$. Nos planejamentos terapêuticos dos pacientes III e IV, a endodontia foi incluída com o intuito de preservar a arcada dentária natural, a dimensão vertical e, também, para adiar a necessidade de um tratamento cirúrgico definitivo em pacientes jovens.

O tratamento ortodôntico para pacientes com DI não é um procedimento muito indicado. Frequentemente, esses pacientes apresentam-se com dentes frágeis, mobilidade acentuada e baixa resistência à fratura. A movimentação ortodôntica envolve um determinado risco, no entanto, acredita-se que pode ser concluída com sucesso ${ }^{6}$. Não foi necessário realizar esse tipo de tratamento em nenhum dos casos até o presente momento.

Por não apresentar fragilidade óssea, os casos de DI tipo II possibilitam utilizar como opção terapêutica a colocação de implantes dentários e prótese sobre implantes. Tal protocolo tem demonstrado sucesso na literatura ${ }^{7,8,11,13}$ e condiz com o plano de tratamento que foi proposto para os casos I e II.

\section{Considerações finais}

A dentinogênese imperfeita é um distúrbio que causa prejuízos físicos, funcionais e emocionais aos seus portadores. No entanto, nota-se que há poucos avanços nas alternativas de tratamento que pos- 
sam minimizar esses prejuízos. Em síntese, sugere-se que a melhor maneira de reduzir esses agravos é a realização de um diagnóstico preciso e prematuro da doença, para que, desse modo, seja possível a realização de tratamentos adequados para cada tipo de DI. Assim, estaria assegurada a possibilidade de sempre evitar os danos que essa anomalia causa aos seus portadores.

\section{Abstract}

Objective: This study reports the diagnosis method used to identify dentinogenesis imperfecta in six patients of the same family. Case reports: Family diagnosis was established from the anamnesis of the proband and later other family members were asked to attend the service. A pooled analysis of clinical, physical, image, and biochemical tests was performed to complete the final diagnosis. Treatment protocol was performed individually according to the clinical condition of each patient. Final considerations: Dentinogenesis imperfecta is considered a genetic disorder in dentin development, which occurs in the absence of systemic disorders. It is an autosomal-dominant disorder and might be caused by mutations of dentin sialophosphoprotein gene DSPP. Clinically, it may present enamel translucency, dark coloring, and dentin brittleness, which may lead to severe functional and aesthetic damages to the patient. Hence, diagnosis should be thorough and early, thus avoiding more complex therapeutic interventions with increasing age.

Keywords: Pathology. Diagnosis. Complications. Dentinogenesis imperfecta.

\section{Referências}

1. Neville BW, Damm DD, Allen CM, Bouquot JE. Oral and Maxillofacial Pathology. 3. ed. St. Louis: Saunders Elsevier; 2008.

2. Lee SK, Hu JC, Lee KE, Simmer JP, Kim JW. A dentin sialophosphoprotein mutation that partially disrupts a splice acceptor site causes type II dentin dysplasia. J Endod 2008; 34:1470-3.

3. Beattie ML, Kim JW, Gong SG, Murdoch-Kinch CA, Simmer JP, Hu JC. Phenotypic variation in dentinogenesis imperfecta/dentin dysplasia linked to 4q21. J Dent Res 2006; 85:329-33.

4. Barron MJ, McDonnell ST, MacKie I, Dixon MJ. Hereditary dentine disorders: dentionogenesis imperfectaa and dentine dysplay. Orphanet J Rare Dis 2008; 3:31.

5. Kim JW, Simmer JP. Hereditary dentin defects. J Dent Res 2007; 86:392-9.

6. Kindelan J, Tobin M, Roberts-Harry D, Loukota RA. Orthodontic and orthognathic management of a patient with osteogenesis imperfecta and dentinogenesis imperfecta: a case report. J Orthod 2003; 30:291-6.

7. Ysmayel AES. Tratamiento prostodóntico en paciente con dentinogénesis imperfecta: reporte de un caso. Acta Odontol 2000; 38:49-55.

8. Henke DA, Fridrich TA, Aquilino SA. Occlusal rehabilitation of a patient with dentinogenesis imperfecta: a clinical report. J Prosthet Dent 1999; 81:503-6.
9. Sillence DO, Senn A, Danks DM. Genetic heterogeneity in osteogenesis imperfecta. J Med Genet 1979; 16:101-16.

10. Moundouri-Andritsakis H, Kourtis S, Andritsakis DP. All-ceramic restorations for complete-mouth rehabilitation in dentinogenesis imperfecta: a case report. Quintessence Int 2002; 33:656-60.

11. Knezevic A, Tarle Z, Panduri $\square$ V. Esthetic reconstruction of teeth in patient with dentinogenesis imperfecta-a case report. Coll Antropol 2006; 30:231-34.

12. Singhal P, Arya S, Vengal M, Bhalodia M, Patil N, Pati A. Dentinogenesis Imperfecta Type II-A Case Report with Review of Literature. Global Journals Inc 2014; 14:25-8.

13. Seymour DW, Chan MF, Nixon PJ. Dentinogenesis Imperfecta: Full-Mouth Rehabilitation using Implants and Sinus Grafts - a case report. Dent Update 2012; 39:498-504.

14. Santili C, Akkari M, Waisberg G, Bastos Júnior JO, Ferreira WM. Clinical, radiographic and laboratory evaluation of patients with osteogenesis imperfecta. Rev Assoc Med Bras 2005; 51:214-20.

15. Pereira AS, Pinto MM, Silva LR, Rego MA, Bussadori SK. Tratamento clareador conservador com peróxido de hidrogênio (35\%) na dentinogênese imperfeita. Rev Paul Odontol 2005; 27:4-7.

\section{Endereço para correspondência:}

Viviane Palmeira da Silva

Ramiro Barcelos, 2.492, sala 503

90035-003 Porto Alegre-RS

Telefone: (51) 8214-9580 / (51) 3308-5011

E-mail: vivipalmeirasilva591@gmail.com

Recebido: 01/03/16. Aceito: 13/06/16. 